\title{
Biosecurity and herd health management practices on Canadian dairy farms
}

\author{
J. Denis-Robichaud, ${ }^{1}$ D. F. Kelton, ${ }^{2}$ C. A. Bauman, ${ }^{2}$ H. W. Barkema, ${ }^{3}$ G. P. Keefe, ${ }^{4}$ and J. Dubuc ${ }^{5 *}$ \\ ${ }^{1}$ Independent researcher, Amqui, QC, Canada, G5J 2N5 \\ ${ }^{2}$ Department of Population Medicine, University of Guelph, Guelph, ON, Canada, N1G 2W1 \\ ${ }^{3}$ Department of Production Animal Health, University of Calgary, Calgary, AB, Canada, T2N 1N4 \\ ${ }^{4}$ Department of Health Management, University of Prince Edward Island, Charlottetown, PE, Canada, C1A 4P3 \\ ${ }^{5}$ Département de Sciences Cliniques, Faculté de Médecine Vétérinaire, Université de Montréal, St-Hyacinthe, QC, Canada, J2S 2M2
}

\section{ABSTRACT}

The Canadian dairy industry has created national standards to support the adoption of biosecurity practices and to reduce disease risks across the country. There is, however, very little information on the adoption of these practices. The present study aimed to describe the adoption of biosecurity practices on Canadian dairy farms shortly after the creation of the national standards and to identify demographic factors associated with practice adoption. In 2015, 2 questionnaires (phase 1 and 2) were administered to Canadian dairy farmers during an extensive cross-sectional study. Associations between adoption of biosecurity practices as well as associations between adoption of these practices and demographic variables were tested using multiple correspondence analysis. A total of 1,157 questionnaires were completed in phase 1 , and a subsample of 368 respondents was selected using stratified random sampling to complete phase 2 during visits to the farms. There was a lack of investigation into general disease syndromes such as a high prevalence of abortion or an unexplained death (38 and $22 \%$ of respondents, respectively). Biosecurity measures within herds and between herds to minimize the spread of infection were not widely adopted (e.g., $27 \%$ of the respondents never housed sick or lame animals in their calving pen, $41 \%$ had closed herds, and 25 and $48 \%$ of the open herds had no strategy for introducing new additions and reintroducing returning animals, respectively). Cleanliness of the cows before calving was always ensured by $29 \%$ of the respondents, and $27 \%$ of the respondents reported always sanitizing the calving pen after each calving. Less than $15 \%$ of the respondents had measures in place to limit or control visitors coming on their farm. Moreover, less than half of the respondents reported requiring family members, employees, and

Received October 30, 2018

Accepted May 17, 2019.

*Corresponding author: jocelyn.dubuc@umontreal.ca visitors to wear farm-designated or clean boots and coveralls. From the multiple correspondence analysis, 2 dimensions were retained and were summarized as "animal movement, calving area, and visitor biosecurity" and "employee biosecurity." Geographical region, type of housing, and milk production were associated with the "employee biosecurity" dimension. The present study demonstrates that many important biosecurity practices are not implemented on Canadian dairy farms; therefore, efforts to promote the adoption of these practices will be necessary to improve biosecurity in dairy herds.

Key words: disease introduction, disease spread, health management, sanitation

\section{INTRODUCTION}

In animal production, biosecurity refers to management practices implemented to prevent the introduction and the spread of infectious diseases (Dargatz et al., 2002; DEFRA, 2003; Brennan and Christley, 2012). Studies have shown biosecurity to be associated with reduced odds of diseases, improved productivity, and decreased use of antimicrobials (Lindberg and Houe, 2005; Laanen et al., 2013; Oliveira et al., 2017). Even though specialists and government agencies recommend implementation of biosecurity practices on dairy farms (Villarroel et al., 2007; Kuster et al., 2015; Shortall et al., 2017), their adoption seems to be limited. For example, uncommonly adopted practices include disease testing and isolating new and returning animals, controlling visitor access or requiring them to wear designated footwear and clothes, and using the hospital pen exclusively for sick animals (Moore et al., 2010; Sarrazin et al., 2014; Emanuelson et al., 2018).

In 2013, the Canadian Food Inspection Agency and the Dairy Farmers of Canada (the national organization representing all dairy farmers in Canada), in collaboration with producers, academia, and provincial governments, proposed the National Standard for Biosecurity for Canadian Dairy Farms and an accompany- 
ing Producer Planning Guide (CFIA, 2013a,b). These documents aim to support producers in implementing industry-wide biosecurity practices for reducing disease risk by offering farm-based biosecurity plans and strategies. The target outcomes of the national standard are to (1) have an effective animal health management plan in place and actively used (animal health management), (2) purchase and move cattle in a manner that minimizes the risk of introduction and spread of infectious diseases (animal addition and movement), (3) establish maintenance and sanitation programs for the animal facility to reduce the pathogen load and to minimize the risk of introduction and further spread of diseases (premises management and sanitation), and (4) ensure that farm employees, consultants, and visitors are aware of and follow farm biosecurity measures (personnel, visitors, vehicles, and equipment; CFIA, 2013a).

While the implementation of the national standards is not mandatory, the proAction program is a Canadian national quality assurance program for ensuring milk quality and animal and environmental stewardship that requires Canadian dairy farmers to meet specific biosecurity targets. The program has been implemented on Canadian dairy farms since 2017 and would benefit from benchmarks. Surveys of biosecurity practice adoption have been conducted in the United States (Moore et al., 2010; Negrón et al., 2011), Europe, (Sayers et al., 2013; Sarrazin et al., 2014; Emanuelson et al., 2018), United Kingdom (Brennan and Christley, 2012), and Australia (Ridge et al., 2010); however, the only available Canadian data on biosecurity practices are disease specific (Johne's disease) and related to one province (Pieper et al., 2015). Broadening this knowledge could help inform the implementation of the national standard through the proAction program. Moreover, understanding demographic factors associated with the adoption of biosecurity and health management practices could support the development of the tailored approach required by proAction. Indeed, the adoption of biosecurity practices has been associated with regional location and farm characteristics as well as the respondents' personality in other countries (Kristensen and Jakobsen, 2011; Sayers et al., 2013; Ritter et al., 2016). The objectives of the present study were to describe the current adoption of biosecurity practices on Canadian dairy farms and to identify demographic factors that were associated with adoption of these practices.

\section{MATERIALS AND METHODS}

This study was part of a cross-sectional study focused on health and management of Canadian dairy farms and was approved by the Human Ethics Committee and Animal Care Committees of each participating university: University of Calgary (REB\#14-2481, AC15-0048), University of Guelph (REB\#14DC025, AUP\#3320), Université de Montréal (15-007-CE- RESD, 15-Rech-1786), University of Prince Edward Island (REB\#6006095, AUP\#15-106), and University of Saskatchewan (AUP\#20150037). The 2 phases of this study were described in detail by Bauman et al. (2018).

\section{Phase 1: Questionnaire}

Briefly, phase 1 was a questionnaire developed by a team of researchers at the 5 veterinary colleges in Canada. The questionnaire was pretested, translated, and validated before being administered to Canadian dairy producers between March 1 and April 30, 2015. The English version of the 189-question questionnaire is available online (www.nationaldairystudy.ca/the -study). The questions were multiple-choice questions with single-answer $(\mathrm{n}=76)$ and multiple-answer $(\mathrm{n}=$ 40) options, open-ended questions $(\mathrm{n}=25)$, matrix tables $(\mathrm{n}=26)$, slider scale questions $(\mathrm{n}=6)$, drop-down menus $(\mathrm{n}=3)$, and constant sum questions (entries must total up; $\mathrm{n}=13$ ). The questionnaire was divided into the following subcategories: background information of the producer and farm characteristics, biosecurity and infectious diseases, calf health, animal welfare, lameness and hoof health, udder health and milking hygiene, reproductive health, and use of internet and social media. No sample size calculation was done for this phase as every dairy producer in the country was invited to participate in the study, and the goal was to collect information from as many producers as possible. Every licensed dairy producer in Canada is registered with a provincial milk marketing board and was invited to participate via a letter. Participation was facilitated by offering various means of access to the survey in both English and French: an online platform (Qualtrics; http://www.qualtrics.com/), a paper questionnaire by mail (paid postage), and a verbal questionnaire over the phone (toll-free number). Respondents were encouraged to participate by ensuring their confidentiality using a unique, confidential code and by offering a Can $\$ 20$ gift card to a national chain of coffee shops as an incentive to the first 250 respondents (Dillman et al., 2008; Dohoo et al., 2009).

\section{Phase 2: Farm Visit}

In phase 2, a subset of farms was visited to gather more detailed information using a second questionnaire, take animal-based measures, collect biological samples from a subset of animals, and evaluate some management practices. Only the questionnaire was used for 
the present study. Farms were visited between May 10 and August 30, 2015, with a target sample size of 368 farms determined using the prevalence for common endemic diseases such as Staphylococcus aureus, with an expected herd-level prevalence of $40 \%$ (Olde Riekerink et al., 2010), 95\% confidence and $80 \%$ power (Dohoo et al., 2009), the costs of travel to more remote regions, and the sampling staff available. Farms were selected from the phase 1 respondents using stratified random sampling to ensure fair representation by province and to include herds enrolled and not enrolled in milk recording, as the enrollment of Canadian farms in milk recording is approximately 75 to $80 \%$ (CDIC, 2015). Farm visits were carried out by 14 university students who received standardized training over $3 \mathrm{~d}$. The training included farm selection, questionnaire administration, sample collection, and animal assessment. The second questionnaire administered to the producers during the farm visit consisted of 149 questions. The question format breakdown was 111 multiple-choice questions with a single-answer option, 13 multiplechoice questions with a multiple-answer option, 18 open-ended questions, 5 matrix, and 2 slider questions. The subcategories of the questionnaire were biosecurity, antimicrobial use, calf health, down cow scenario, and the role of veterinarians. The administration of the questionnaire was not compared between students, but the interrater agreement and expert-trainee agreement of the animal-based measures by the student were substantial (Byrt's к: 0.66 to 1.00; Croyle et al., 2018).

From all respondents, monthly volume of shipped milk was obtained from each provincial marketing board for January 1, 2014, to August 30, 2015. Farms were categorized based on monthly milk sales using the interquartile ranges as very small $(<27,000 \mathrm{~kg} / \mathrm{mo})$, small $(27,000-40,000 \mathrm{~kg} / \mathrm{mo})$, medium (40,000-63,000 $\mathrm{kg} / \mathrm{mo})$, and large $(>63,000 \mathrm{~kg} / \mathrm{mo})$. Herds were also categorized according to their geographical region. Operations in Ontario and Québec were categorized accordingly, whereas farms in British Columbia, Alberta, Saskatchewan, and Manitoba were grouped together as western provinces, and farms from New Brunswick, Nova Scotia, Prince Edward Island, and Newfoundland were grouped together as eastern provinces. Farms were grouped based on lactating cows being housed in a tiestall or in loose housing, with freestall and bedded pack being combined in the loose-housing group. Finally, farms were categorized according to their organic certification or not (conventional).

\section{Statistical Analyses}

Statistical analyses were conducted using $\mathrm{R}$ version 3.4.3 (R Core Team, 2015). Mean, median, and inter- quartile range were calculated for continuous and ordinal variables. Proportions ( \pm standard error) for binary and categorical variables were adjusted for geographical region according to the distribution of Canadian dairy farms (CDIC, 2015). Multiple correspondence analysis (MCA; Husson et al., 2017) was used to summarize associations between the reported adoption of different health management practices within farms. Variables were created from each stand-alone herd health management question and were included as active variables in the analysis $(\mathrm{n}=28$; Supplemental Tables S1-S7, https://doi.org/10.3168/jds.2018-15921). Demographic variables were included as additional supplementary categorical variables $(\mathrm{n}=7$; region, housing, herd milk production, age, education, role on the farm of the respondent, and organic status of the farm). To minimize the number of missing values, only respondents who participated in phase 1 and 2 were included for the MCA. Missing values were dealt with using a multiple imputation approach (missMDA package; $\mathrm{R}$ Core Team, 2015), and the MCA was undertaken using the Burt table (FactoMineR package; R Core Team, 2015). Briefly, MCA creates dimensions using the variance of all the observed variables (biosecurity questions) to represent latent variables, and overfitting was avoided using a regularized iterative MCA algorithm (Josse et al., 2012). The dimensions are then presented in descending order of the amount of variation they explain, and the variables contributing the most to the creation of the dimension can be identified. The association among MCA dimensions and reported adoption of biosecurity practices was assessed using the $v$-test, with a $v$-test value $>|2|$ indicative of a variable significantly different from 0. Graphs were obtained to visualize (1) correlation between variables and the dimensions, (2) correlation between the categories and the dimensions as well as the contribution of categories to the dimensions, and (3) distribution of respondents within supplementary variables (factoextra package; $\mathrm{R}$ Core Team, 2015). The latter also allowed visualization of the respondent central tendency (barycenter) within a category and its $95 \%$ confidence ellipse, which was used to evaluate the difference between supplemental categories (if the confidence ellipses are not superimposed, the categories within a variable were considered significantly different; Husson et al., 2017).

\section{RESULTS}

\section{Respondents}

A total of 1,157 questionnaires (phase 1) were available for analyses, which represented $10 \%$ of the 11,664 active Canadian producers in 2015. A total of 374 of 
the phase 1 respondents were visited and completed the supplementary questionnaire (phase 2). Of the visited farms, 6 respondents were not involved in the biosecurity practices on the farm, resulting in 368 available questionnaires for the present study. The number of answers per question varied as respondents were allowed to skip questions. The percentage of missing data ranged from $0 \%$ for "geographical region" to $10.7 \%$ for "shared vehicles or equipment with a neighbor's farm." Demographic data of phase 1 and 2 respondents are presented in Table 1. In 2015, the distribution of Canadian dairy farms was as follows (CDIC, 2015): western provinces, $12 \%(\mathrm{n}=1,446)$; Ontario, $33 \%(\mathrm{n}=3,834)$; Québec, 49\% ( $\mathrm{n}=5,766)$; and eastern provinces, $6 \%$ $(\mathrm{n}=637)$; this differs from the distribution in both phase 1 and phase $2(P<0.01$; Table 1$)$. The difference between the unadjusted and adjusted results for geo- graphical region ranged from $-1.7 \%$ to $+2.2 \%$ (median $=-0.1 \%$ ) for phase 1 questions and $-3.2 \%$ to $+6.5 \%$ $($ median $=-0.5 \%)$ for phase 2 questions.

\section{Animal Health Management}

Most respondents kept health records (93\%), but less than half $(45 \%)$ reported that their veterinarian reviewed the occurrence of diseases in the herd at least once a year (Supplemental Table S1, https://doi.org/ 10.3168/jds.2018-15921). Written standard operating procedures for dealing with specific cases of infectious diseases were used by $63 \%$ of the respondents, mainly for mastitis cases. Seventy percent of the respondents used written vaccination programs, most (85\%) of which were reviewed annually by a veterinarian.

Table 1. Proportion of respondents, classified by demographic variable (geographical region, type of housing, herd milk production, age, and highest level of education), to a questionnaire administered to Canadian dairy producers (phase 1) and to a follow-up questionnaire administered to a subgroup of respondents (phase 2)

\begin{tabular}{|c|c|c|c|c|c|c|}
\hline \multirow[b]{2}{*}{ Variable } & \multicolumn{3}{|c|}{ Phase $1(\mathrm{n}=1,157)$} & \multicolumn{3}{|c|}{ Phase $2(\mathrm{n}=368)$} \\
\hline & $\mathrm{n}$ & $\%^{1}$ & $\mathrm{SE}$ & $\mathrm{n}$ & $\%^{1}$ & $\mathrm{SE}$ \\
\hline \multicolumn{7}{|l|}{ Geographical region } \\
\hline Western provinces $^{2}$ & 160 & 13.8 & 1.0 & 55 & 15.0 & 1.9 \\
\hline Ontario & 401 & 34.7 & 1.4 & 133 & 36.1 & 2.5 \\
\hline Québec & 509 & 44.0 & 1.5 & 121 & 32.9 & 2.4 \\
\hline Eastern provinces ${ }^{3}$ & 87 & 7.5 & 0.8 & 59 & 16.0 & 1.9 \\
\hline \multicolumn{7}{|l|}{ Type of housing } \\
\hline Tiestall & 678 & 58.8 & 1.4 & 165 & 45.0 & 2.6 \\
\hline Loose & 476 & 41.2 & 1.4 & 202 & 55.0 & 2.6 \\
\hline \multicolumn{7}{|l|}{ Herd milk production } \\
\hline Very small $(<27,000 \mathrm{~kg} / \mathrm{mo})$ & 204 & 18.2 & 1.1 & 53 & 15.2 & 1.9 \\
\hline Small $(27,000-40,000 \mathrm{~kg} / \mathrm{mo})$ & 268 & 23.8 & 1.3 & 75 & 21.6 & 2.2 \\
\hline Medium $(40,000-63,000 \mathrm{~kg} / \mathrm{mo})$ & 291 & 25.9 & 1.3 & 86 & 24.7 & 2.3 \\
\hline Large $(>63,000 \mathrm{~kg} / \mathrm{mo})$ & 361 & 32.1 & 1.4 & 134 & 38.5 & 2.6 \\
\hline \multicolumn{7}{|l|}{ Organic certification } \\
\hline Conventional & 1,121 & 97.0 & 0.5 & 354 & 96.5 & 1.0 \\
\hline Organic & 35 & 3.0 & 0.5 & 13 & 3.5 & 1.0 \\
\hline \multicolumn{7}{|l|}{ Age of respondent } \\
\hline$<30$ yr & 163 & 14.1 & 1.3 & 59 & 16.1 & 2.3 \\
\hline $30-39$ yr & 289 & 25.1 & 1.3 & 101 & 27.6 & 2.3 \\
\hline $40-49$ yr & 275 & 23.9 & 1.3 & 81 & 22.1 & 2.2 \\
\hline $50-59$ yr & 335 & 29.1 & 1.3 & 102 & 27.9 & 2.3 \\
\hline$\geq 60 \mathrm{yr}$ & 90 & 7.8 & 0.7 & 23 & 6.3 & 1.2 \\
\hline \multicolumn{7}{|c|}{ Level of education (highest achieved) } \\
\hline Primary school & 17 & 1.5 & 0.4 & 3 & 0.8 & 0.5 \\
\hline Middle school & 100 & 8.7 & 0.8 & 37 & 10.1 & 1.6 \\
\hline High school & 285 & 24.7 & 1.3 & 82 & 22.4 & 2.2 \\
\hline College diploma & 547 & 47.4 & 1.5 & 169 & 46.2 & 2.6 \\
\hline College degree & 39 & 3.4 & 0.5 & 22 & 6.0 & 1.2 \\
\hline University degree & 144 & 12.5 & 1.0 & 43 & 11.8 & 1.7 \\
\hline Postgraduate degree & 21 & 1.8 & 0.4 & 10 & 2.7 & 0.9 \\
\hline \multicolumn{7}{|l|}{ Role on the farm } \\
\hline Owner & 1,045 & 90.4 & 1.0 & 333 & 90.8 & 1.7 \\
\hline Manager & 83 & 7.3 & 0.8 & 28 & 7.6 & 1.4 \\
\hline Farm worker & 27 & 2.3 & 0.4 & 6 & 1.6 & 0.7 \\
\hline
\end{tabular}

${ }^{1}$ Sum of the categories within a variable within a column equals $100 \%$.

${ }^{2}$ British Columbia, Alberta, Saskatchewan, and Manitoba.

${ }^{3}$ New Brunswick, Nova Scotia, Prince Edward Island, and Newfoundland. 
Table 2. Summary of the strategies used, at least occasionally, for newly added cattle and returning cattle on Canadian dairy farms, adjusted for geographical region

\begin{tabular}{|c|c|c|c|}
\hline \multirow[b]{2}{*}{ Phase } & \multirow[b]{2}{*}{ Strategy ${ }^{1}$} & \multicolumn{2}{|c|}{$\begin{array}{l}\text { Proportion }( \pm \mathrm{SE}) \\
\text { of respondents, \% }\end{array}$} \\
\hline & & New cattle & Returning cattle \\
\hline 1 & Tested the new addition or returning cattle for disease(s) of concern ${ }^{2}$ & $25.0( \pm 1.9)$ & $2.7( \pm 0.9)$ \\
\hline \multirow[t]{2}{*}{1} & Vaccinated the new addition or returning cattle & $56.8( \pm 2.1)$ & $40.9( \pm 2.8)$ \\
\hline & None & $24.8( \pm 1.9)$ & $47.9( \pm 2.9)$ \\
\hline
\end{tabular}

\footnotetext{
${ }^{1}$ Strategies respondents implemented in 2014. Respondents could choose more than 1 strategy.

${ }^{2}$ The diseases of concerns tested by most respondents were contagious mastitis, enzootic bovine leukosis, neosporosis, Johne's disease, and bovine viral diarrhea.
}

Nonspecific syndromes such as a high prevalence of abortions ( $>5$ abortions/100 calvings) or an unexplained death or euthanasia were investigated by 38 and $22 \%$ of the respondents, respectively (Supplemental Table S1, https://doi.org/10.3168/jds.2018-15921). The reasons for not investigating the cause of abortions were concern about the cost and resources involved in testing $(50 \%)$, no interest in testing $(29 \%)$, or not being aware of the importance of testing (21\%).

Measures for separating groups of animals susceptible to infectious diseases were adopted to various extents (Supplemental Table S2, https://doi.org/10.3168/jds .2018-15921). For example, $52 \%$ of the respondents never allowed newborns to nurse the dam and $57 \%$ always used a new needle for each animal when vaccinating or treating animals, but only $27 \%$ never housed sick or lame cows in calving pens. Respondents reported housing their preweaned heifers individually (63\%), in pairs (11\%), and in groups of 3 or more (26\%).

\section{Animal Addition and Movement}

Although more than half of the respondents (55\%) considered their herd closed in 2014 (answered yes to "Did you consider your herd a closed herd?"), only $41 \%$ truly had a closed herd (answered no to both "Were any adult cattle or youngstock added to this dairy farm during 2014?" and "Did any cattle temporarily leave your farm [. . .] and then return?"). Most cattle were purchased directly from another farm, and $13 \%$ of the respondents bought cattle from multiple sources (Supplemental Table S3, Supplemental Figure S1, https:// doi.org/10.3168/jds.2018-15921).

For both newly acquired and returning cattle, vaccination was more commonly used than segregation and disease testing (Table 2). Of the respondents who tested newly added cattle for diseases, $46 \%$ did so before the animal arrived on farm, $15 \%$ did so after the animal arrived on farm but before it entered the herd, and $39 \%$ did so after the animal arrived and entered the herd. Respondents tested for 1 (26\%), 2 (34\%), 3 (25\%), or more than $3(15 \%)$ diseases. The pathogens tested by most respondents were contagious mastitis pathogens (60\%), bovine leukemia virus (59\%), Neospora spp. (51\%), Mycobacterium avium ssp. paratuberculosis (25\%), and bovine viral diarrhea virus (17\%). In $38 \%$ of the farms, the cattle had direct contact with at least one other species of farm or wildlife animal, and $67 \%$ had direct contact with pet dogs or barn cats.

\section{Sanitation}

Although $65 \%$ of the respondents never used feeding equipment (e.g., shovel) for both food and manure, 27 to $30 \%$ of the respondents always performed other practices to keep the cows and the calving pens clean around calving (Supplemental Table S4, https://doi .org/10.3168/jds.2018-15921). Calf and cow carcasses were buried, composted, removed by a licensed deadstock collector, or incinerated in $92 \%$ of the farms (Supplemental Table S4, Supplemental Figure S2, https:// doi.org/10.3168/jds.2018-15921). The other methods of carcass handling included storing or freezing the carcasses until summer $(\mathrm{n}=30)$, with a few respondents stating they fed the carcasses to scavengers $(n=21)$ or pets $(\mathrm{n}=4)$ or left them in the woods $(\mathrm{n}=14)$.

\section{Human and Equipment Movement}

Thirty-three percent of the respondents shared vehicle or equipment with a neighbor's farm, and between 2 and $13 \%$ of the respondents had measures to control access on their farm (Supplemental Table S5, https: //doi.org/10.3168/jds.2018-15921). Consultants such as AI technicians and veterinarians visited the farms most frequently compared with other types of visitors (Supplemental Table S3, https://doi.org/10.3168/jds .2018-15921). Consultants and visitors were required to always wear clean, disposable, or farm-provided footwear, and coveralls, or to change them between 
groups of animals of different age in 28, 11, and $10 \%$ of the farms, respectively (Supplemental Table S6, Supplemental Figure S4, https://doi.org/10.3168/jds $.2018-15921)$. Thirty-one and $49 \%$ of the respondents required their employees to wear coveralls and boots, respectively, designated for working with the dairy herd, despite $41 \%$ reporting that their employees were likely to have direct contact with animals outside of their farm (Supplemental Table S7, https://doi.org/10 .3168/jds.2018-15921).

\section{Associations}

The MCA offered a 59-dimension solution, but, for clarity of the results, only the first 2 dimensions were examined because they accounted for the most variance (Figure 1). The first dimension was named the "animal movement, calving area, and visitor biosecurity" dimension because the variables contributing the most to the variation of that dimension were the ones addressing the adoption of biosecurity practices for the new animals, the cleanliness of the cows and pen around calving, and the requirement of footwear for visitors of the farm. The second dimension was named the "employee biosecurity" dimension because the variables contributing the most were associated with the requirement of footwear and coveralls for employees and coveralls for visitors. The animal movement, calving area, and visitor biosecurity dimension accounted for $14.5 \%$ of the variance in the data, whereas the employee biosecurity dimension accounted for $8.2 \%$ of the variance in the data. Geographical region, herd milk production, and type of housing were all associated with the employee biosecurity dimension, and organic certification status was associated with the animal movement, calving area, and visitor biosecurity dimension (Figure 2). For geographical region, Ontario and the western and eastern provinces did not differ from each other, but they all differed from Québec province, which was slightly away on the positive pole of the employee biosecurity dimension (Figure 3). Similarly, farms with very small, small, and medium milk production did not differ from each other, but all differed from large production, which was on the negative pole of the employee biosecurity dimension (Figure 3). Tiestall housing was on the positive pole of both the employee biosecurity and animal movement, calving area, and visitor biosecurity dimensions, whereas loose housing was on the negative pole of these dimensions (Figure 3). Finally, the greater difference was observed between conventional and organic farms, the latter being on the negative pole of the animal movement, calving area, and visitor biosecurity dimension (Figure 3).

\section{DISCUSSION}

The objectives of this part of the National Dairy Study were to describe the adoption of biosecurity practices on Canadian dairy farms to identify gaps for the national standard (CFIA 2013a) and to evaluate the association between demographic characteristics and the adoption of biosecurity and health management practices. The National Dairy Study was advertised to all Canadian dairy farmers, with incentives and multiple options available to complete the questionnaire. Ten percent of Canadian dairy producers answered the questionnaire (phase 1), which is considered a low response rate (Dohoo et al., 2009). Previous surveys conducted in the Canadian dairy industry have, however, reported a similar response rate (Neves and LeBlanc, 2015; Denis-Robichaud et al., 2016). The similar distribution between the questionnaire respondents (phase 1) and the population of Canadian dairy producers in 2015 (CFIA, 2013a) suggests that the volunteer (selection) bias was limited. The small variation between the unadjusted and adjusted results suggests that the answers to the questionnaire are likely to represent the Canadian dairy producers. The stratified sampling for the second questionnaire (phase 2) resulted, however, in a smaller proportion of respondents from Québec and a higher proportion from the other regions compared with the proportions in Canada in 2015 (CFIA, 2013a). This discrepancy also resulted in a greater variation between the unadjusted and adjusted results. Despite this potential selection bias, we believe that the results from this study are likely representative of the adoption of biosecurity practices on Canadian dairy farms and can be used for identifying gaps and benchmarking for the industry. Moreover, the associations between demographic characteristics and the adoption of different practices should not have been influenced by this bias.

Keeping good health records, using standardized protocols and vaccination for specific diseases, investigating disease causes, and separating susceptible animals are tools for limiting the entrance and the spread of diseases. Similar to the present study, European surveys reported that health records were kept by 73 to $91 \%$ of dairy farmers (Brennan and Christley, 2012; Sayers et al., 2013; Emanuelson et al., 2018). However, the current study found that dairy farmers perceived that the occurrence of diseases was not, or not frequently, reviewed by their veterinarians. It was impossible in the present context to evaluate whether the veterinarians did not review the occurrence of diseases or whether they did without communicating it with the farmers.

Standardized protocols have been recommended in the dairy industry by an expert consortium (Barkema 
et al., 2015) following positive results obtained with udder health management (Raymond et al., 2006; Oliveira and Ruegg, 2014). In the present study, written standard operating procedures were used by more than half of the respondents for dealing with specific cases of infectious disease. Not surprisingly, the standard operating procedures most commonly found on farms were for mastitis and metritis cases.

Disease investigations of unexplained deaths and abortions were not frequent. For example, only $37 \%$ of respondents with a high prevalence of abortion investigated to identify the cause, which is similar to what was reported in farms in Belgium (Sarrazin et al., 2014). Half of the respondents who did not indicated a concern about the resources and costs associated with investigation. Moreover, investigation of abortion cases rarely results in identifying a specific agent (Thurmond and Picanso, 1990). Similarly, almost half of the respondents had at least 1 animal that died from an unknown cause in the previous year, but less than onequarter of them had a postmortem examination done. In large California dairy herds, a similar number of respondents (20\%) reported that a necropsy was done on animals that died from undetermined causes (Moore et al., 2010). Investigating abortions or deaths can be used to determine pathogens that entered or that are circulating in the herd and to put in place the appropriate measures to prevent more spread.

Written vaccination protocols were in place in twothirds of the visited farms. To our knowledge, the use of vaccination protocols was not evaluated previously, but $86 \%$ of the Irish dairy farmers reported administering at least 1 vaccine (Sayers et al., 2013). The present study did not evaluate what vaccines were used, but Villarroel et al. (2007) suggested a tailored vaccination program in each farm, and we found that most of the respondents that had a vaccination protocol had it reviewed by their veterinarian at least once a year.

Measures to separate groups of susceptible animals were adopted to various extents. Surprisingly, the least-adopted practice was to never house sick or lame animals in the calving pen (27\%); in comparison, this practice was adopted by 36 to $70 \%$ of the respondents in previous studies in the United States and Europe (Moore et al., 2010; Sarrazin et al., 2014). Conversely, never allowing the calf to nurse the dam and always

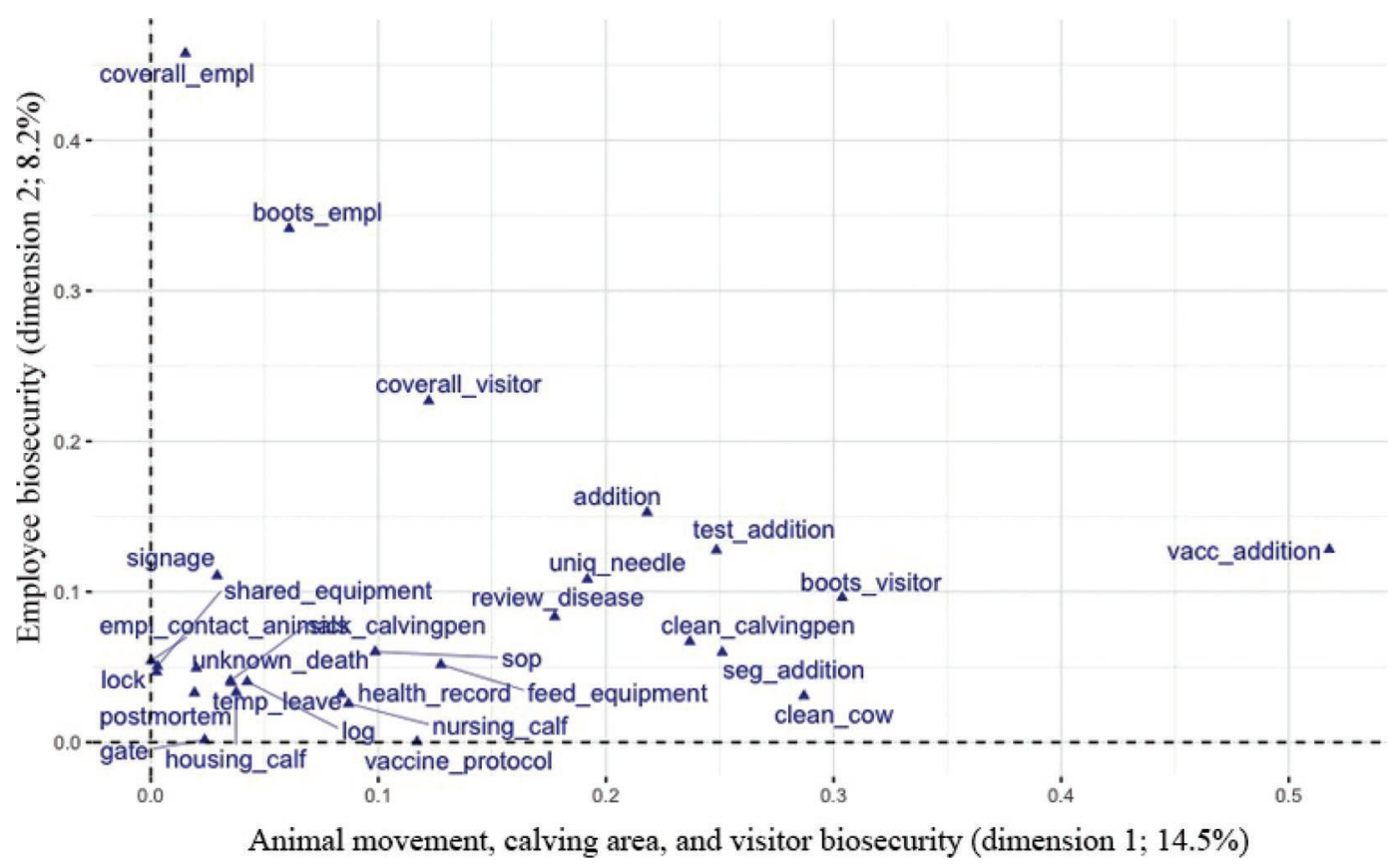

Figure 1. Graphical representation of the correlations among the 28 biosecurity and health management practices adopted on Canadian dairy farms (variables) and the 2 main dimensions of the multiple correspondence analysis of biosecurity and health management practices adopted on Canadian dairy farms. Each variable is represented according to its correlation ratio with the first 2 dimensions. Variables with a greater correlation ratio (closer to 1) with a dimension indicate that the individuals carrying the same category for this variable have similar coordinates in this dimension (Husson et al., 2017) and consequently contribute the most to this dimension. The 2 principal dimensions were named according to the variables that contributed the most. The first dimension, which accounted for $14.5 \%$ of the variance, was named "animal movement, calving area, and visitor biosecurity" because the variables contributing the most were vaccinating (vacc_addition) and testing (test_addition) new additions, requiring visitors to wear boots (boots_visitors), and ensuring cleanliness of the cows (clean_cow) and calving pen (clean_calvingpen) before calving. The second dimension, which accounted for $8.2 \%$ of the variance, was named "employee biosecurity" because the variables contributing the most were the requirement for employees to wear coveralls (coverall_empl) and boots (boots_empl). 


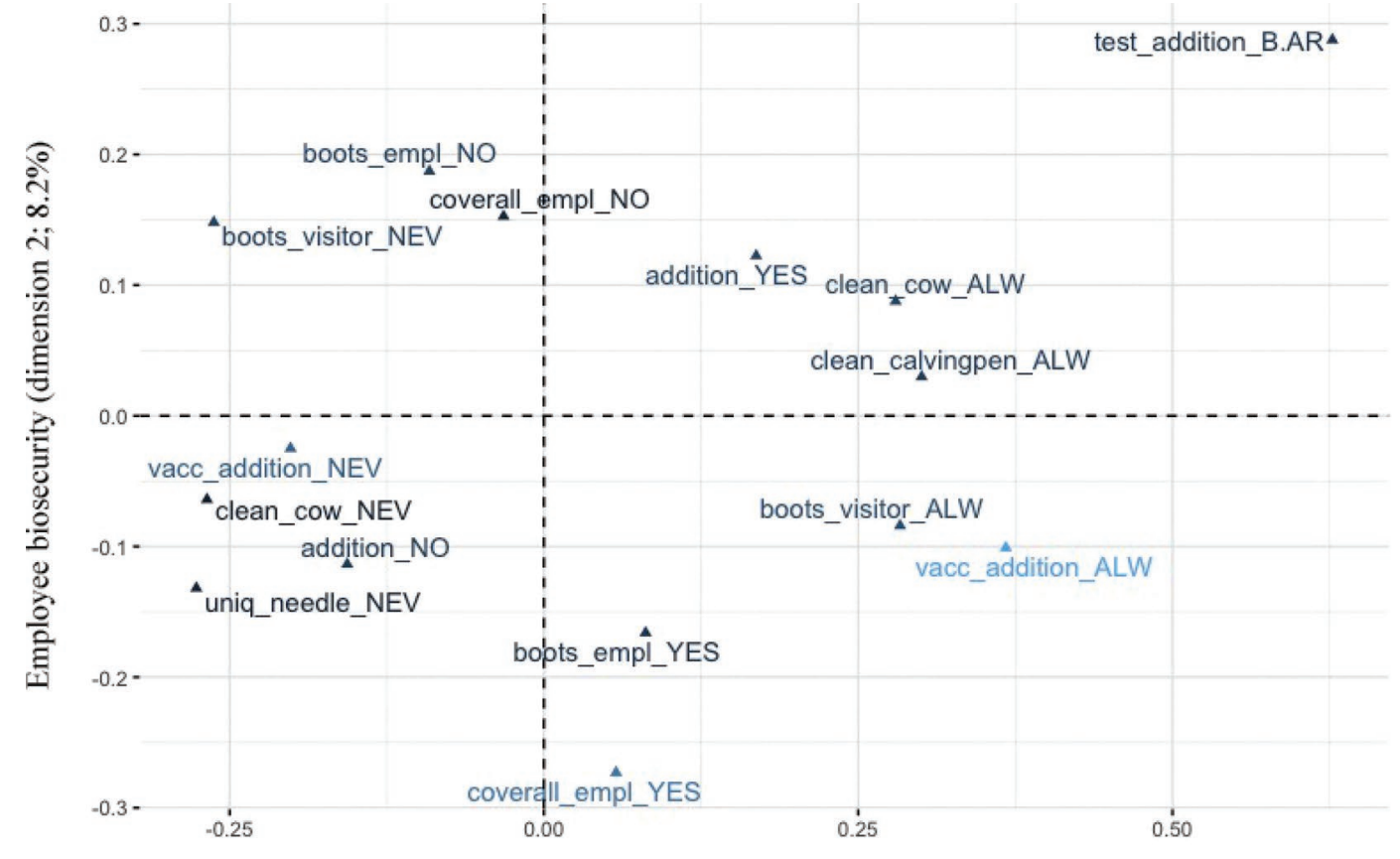

Animal movement, calving area, and visitor biosecurity (dimension $1 ; 14.5 \%$ )

Figure 2. Graphical representation of the correlations among the 15 categories that contribute the most to each pole of the 2 principal dimensions of the multiple correspondence analysis of biosecurity and health management practices adopted on Canadian dairy farms. The 2 principal dimensions were named according to the variables that contributed the most: "animal movement, calving area, and visitor biosecurity" dimension, which accounted for $14.5 \%$ of the variance, and "employee biosecurity" dimension, which accounted for $8.2 \%$ of the variance. The categories selected by individuals in the positive pole of the animal movement, calving area, and visitor biosecurity dimension were testing new additions before their arrival (test_addition_B.AR), always vaccinating new additions (vacc_addition_ALW), always requiring visitors to clean their footwear or wear disposable or farm-provided footwear (boots_visitor_ALW), always cleaning out, sanitizing, and re-bedding the calving pen after each calving (clean_calvingpen_ALW), and always ensuring cows' udder and lower legs were free of manure before calving (clean_cow_ALW). The categories selected by the individuals in the negative pole were never using a unique needle to treat or vaccinate animals (uniq_needle_NEV), never ensuring cows' udder and lower legs were free of manure before calving (clean_cow_NEV), never requiring visitors to clean their footwear or wear disposable or farm-provided footwear (boots_visitor_NEV), and never vaccinating new additions (vacc_addition_NEV). For the employee biosecurity dimension, the categories selected by individuals in the positive pole were not requiring employees to wear boots designated for working with the dairy herd (boots_empl_NO) and not requiring employees to wear coveralls designated for working with the dairy herd (coverall_empl_NO), whereas the categories selected by individuals in the negative pole were requiring employees to wear boots designated for working with the dairy herd (boots_empl_YES) and requiring employees to wear coveralls designated for working with the dairy herd (coverall_empl_YES).

changing the needle between cows were adopted by more than half of the respondents. Perhaps the adoption of these practices is due to their identification as control measures for Johne's disease and bovine leukosis virus, respectively (Erskine et al., 2012; Pieper et al., 2015). Moreover, these 2 practices were adopted by a higher proportion of respondents from Québec, where herd milk production tend to be lower and housing cows in tiestall barns is the most common. As highlighted by Erskine et al. (2012), control measures are often resource demanding and costly, which can be mitigated in smaller tiestall barns.

Although more than half of the respondents considered their herd closed, only $41 \%$ did not add cattle or had cattle returning to their farm in 2014. This proportion is comparable with what was reported in surveys conducted in the United States (Moore et al.,
2010; Negrón et al., 2011) but is likely to be smaller, as Sayers et al. (2013) reported that of the $32 \%$ of herds that self-declared closed, only $12 \%$ were classified as such when using the official national animal identification and movement database. Even though maintaining a closed herd has been identified as an effective biosecurity practice, experts in the dairy industry have considered it impractical to implement (Erskine et al., 2012; Sayers et al., 2014; Shortall et al., 2017).

In herds that added new cattle or had returning cattle, biosecurity practices associated with animal movement were not commonly adopted. In previous studies, purchased cattle were reported to be tested for diseases by 3 to $88 \%$ of the respondents, and, more uniformly, segregated by 13 to $25 \%$ of the respondents (Moore et al., 2010; Sayers et al., 2013; Sarrazin et al., 2014). The introduction of cattle with unknown health status is a 
risk factor for introduction of disease agents onto the farm (Meyling et al., 1990; Radke et al., 2002; Gilbert et al., 2005), and Villarroel et al. (2007) suggested that the low adoption of testing and quarantine of newly acquired animals is likely due to limited practical and economic feasibility but could also be due to a limited perception of threat (Nöremark et al., 2010). Vaccination of newly added cattle, however, was the strategy most adopted by respondents in the present study, which has not been reported by other authors.

A

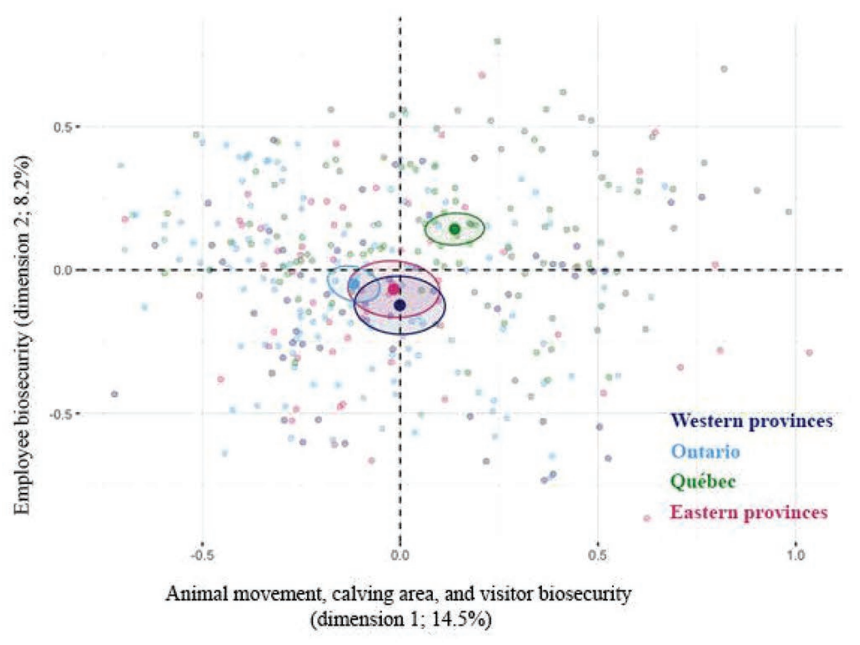

B

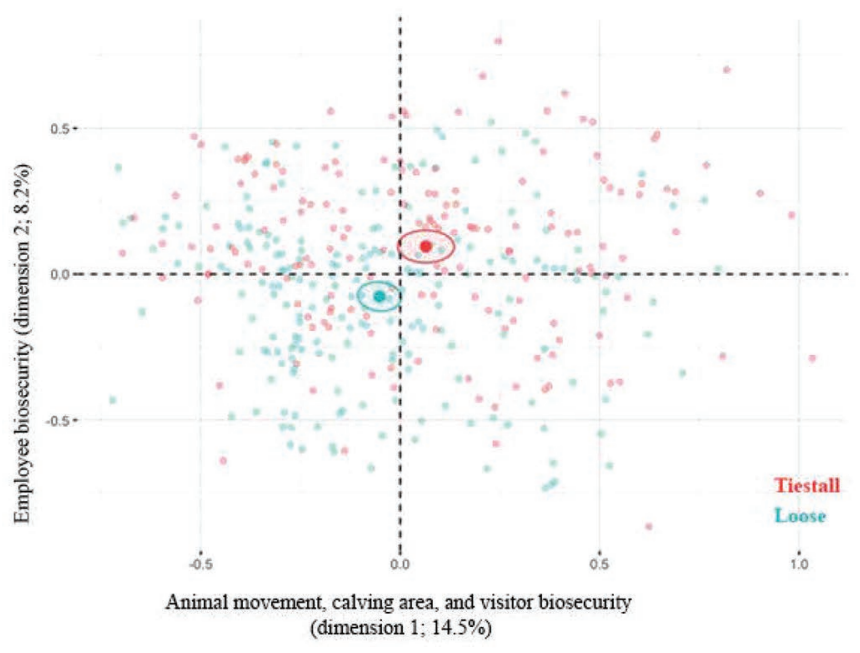

Other than newly added or returning cattle, one-third of the herds were in contact with other farm animals or wildlife. This proportion was comparable with what was reported in previous studies (36-38\%; Moore et al., 2010; Sarrazin et al., 2014). Contact with pet dogs was, however, reported by almost half of the respondents, which is less than what was previously reported $(61 \%$; Sarrazin et al., 2014).

As previously reported, more than $65 \%$ of the respondents never used farm equipment to handle both

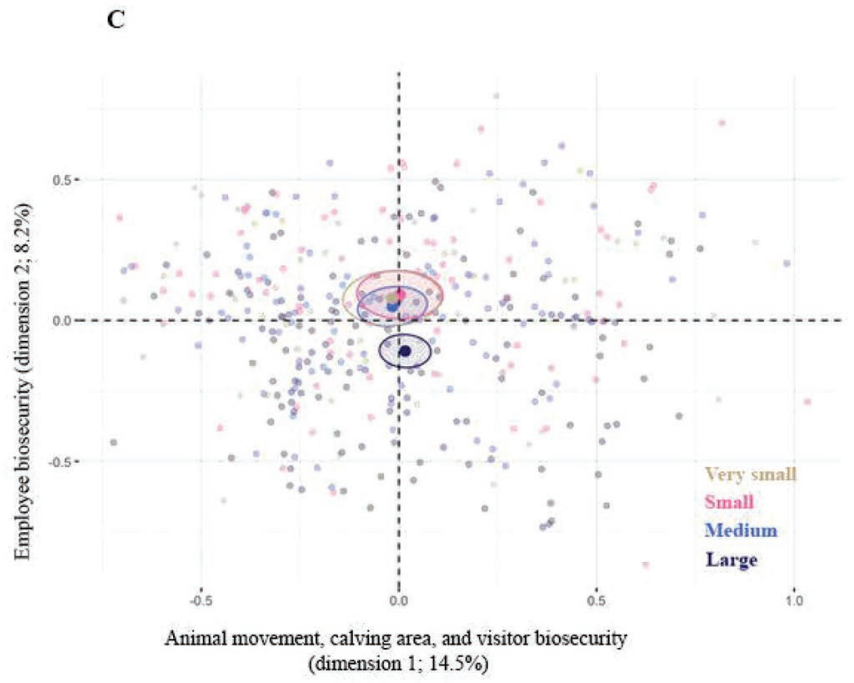

D

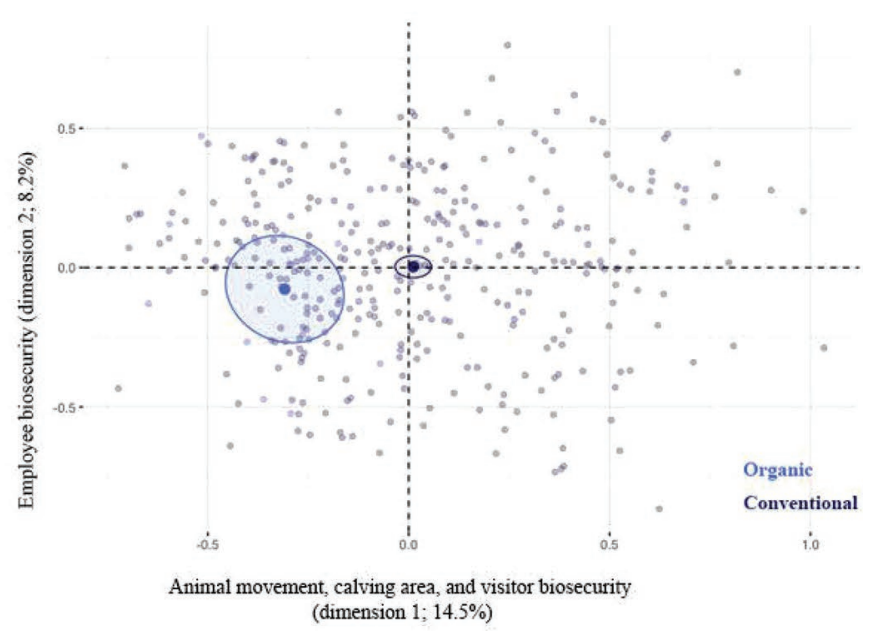

Figure 3. Graphical representation of individuals in the 2 principal dimensions of the multiple correspondence analysis from 28 biosecurity and health management practices adopted on Canadian dairy farms. The distribution of respondents within a supplementary category is represented according to their (A) geographical region, (B) type of housing, (C) herd milk production, and (D) organic certification. For each supplementary category, the central tendency (barycenter) and its $95 \%$ confidence ellipse is represented. The categories within a variable are considered significantly different when the confidence ellipses are not superimposed (Husson et al., 2017). The respondents from Ontario and the eastern and western provinces did not differ from each other, whereas respondents from Québec did. Similarly, respondents with loose housing and tiestall housing differed from each other; very small, small, and medium herds did not differ from each other but differed from large herds; and herds certified as organic differed from conventional herds. 
manure and feed (Moore et al., 2010). The cleanliness of the cows and the calving pens was always ensured by 29 and $26 \%$ of the respondents, respectively, and at least most of the time by more than half of the respondents. Similarly, Sarrazin et al. (2014) reported that $27 \%$ of the respondents cleaned the calving box between each calving. Disposal of carcasses was mostly done by composting, burial, or removal by a deadstock collector in compliance with regulation, but a small proportion used other methods such as feeding them to scavengers.

Measures to control access to the farm, such as gates, locked doors, and visitor logs, were adopted by less than $5 \%$ of the respondents, which is comparable with what was reported elsewhere (Moore et al., 2010). Biosecurity signage was the most commonly adopted practice for restricting access $(14 \%)$, which was also similar to what was reported in the United States (8\%; Moore et al., 2010). Moreover, visitors were always required to wear clean, disposable, or farm-provided boots and coveralls in 27 and $11 \%$ of the operations, respectively. In a previous study, the biosecurity practices required for visitors varied by the type of visitor (veterinarians: $96 \%$; deadstock collectors: 4\%; and farm insurance advisor: 90\%; Brennan and Christley, 2012). This information was not collected by the present survey, but it might be influencing the low proportions observed because visitors who had contact with the animals could have been required to wear boots and coveralls more than visitors who did not. Boots and coveralls designated to the farm were required for employees in a greater proportion of operations (52 and 16\%, respectively). In a survey conducted in Belgium, farm-specific boots and coveralls were present in 70 and $66 \%$ of the farms, respectively, but used in only 20 and $13 \%$ of the farms, respectively (Sarrazin et al., 2014), whereas Moore et al. (2010) reported 17.5 and $10 \%$ of large Californian dairies required both visitors and employees to wear clean boots and clothes, respectively. In the present study, almost half of the respondents reported that their employees were likely to have direct contact with animals outside of their farm, whereas Moore et al. (2010) reported that $85 \%$ of their respondents did not require employees to avoid contact with animals outside of the farm. Finally, one-third of the respondents reported sharing a vehicle with a neighboring farm. In other studies, 36 to $43 \%$ of farmers reported sharing equipment with other farmers (Brennan and Christley, 2012; Sarrazin et al., 2014). Indirect contacts have been shown to be a source of between-farms disease transmission, mainly through fomites such as contaminated clothes, equipment, and vehicles (Sanson et al., 1993; Bates et al., 2001; Nöremark et al., 2013). Disease transmission models also support that personnel and visitor movement likely have an effect on infectious diseases, even though the data on movement and prevention practices are limited (Rossi et al., 2017).

Although most practices were adopted by a limited number of respondents, the consequences of their nonadoption were not evaluated in the present study. The adoption of biosecurity practices has been linked to reduced odds of diseases, improved productivity, and decreased use of antimicrobials (Lindberg and Houe, 2005; Laanen et al., 2013; Oliveira et al., 2017), and it would be interesting to explore these associations in the Canadian context. The present study was conducted shortly after the National Standards for Biosecurity for Canadian Dairy Farms (CFIA, 2013a) were made available and before their mandatory implementation. Future studies might reflect the current changes in the Canadian dairy industry in the adoption of the different practices and perhaps its effect on animal health and productivity.

Twenty-three percent of the variance in the adoption of biosecurity practices was explained by the "animal movement, calving area, and visitor biosecurity" and "employee biosecurity" dimensions. Although this is a small proportion of the overall variance, this situation is common in MCA because the relation between variables is not linear (as in a principal component analysis) but rather is categorical (Husson et al., 2017). Many more dimensions are consequently necessary to explain the relationship between variables. In the present study, for example, the next 2 dimensions obtained from the analysis were also explained by variables related to animal movement, calving area, and visitor biosecurity (results not presented). Although presenting only 2 dimensions limits the understanding of the complex relationships between the variables, it still illustrates the general patterns of biosecurity practice adoption.

The associations found in the present study between the adoption of biosecurity practices and demographic characteristics suggest that a biosecurity plan should be promoted according to geographical region, type of housing, herd milk production, and organic status. For example, farms located in Québec and those with tiestall housing or very low to medium production had their barycenter in the positive pole of the employee biosecurity dimension, where farmers did not require their employees, including family members, to wear boots and coveralls designated for working with the dairy herd. Conversely, farms located in Ontario and the western and eastern provinces and those with loose housing and large production had their barycenter in the negative pole, where farmers did require their employees to wear boots and coveralls designated for 
working with the dairy herd. Even though the distance between these barycenters is relatively small, this result highlights a greater need to address the biosecurity related to employees in the very small to medium tiestall farms in Québec than in the rest of Canada. This association could be due to a different perception of the risk in different Canadian provinces, but the size of the farm and the management also seems to play a role. Further studies using focus groups should increase our understanding of the barriers to adoption and could perhaps explain the difference between regions and type of farm. Similar associations between the adoption of biosecurity practices and both geographical region and herd milk production have also been identified in European countries (Sayers et al., 2013; Sarrazin et al., 2014), but the present study has identified information that can be applied on Canadian dairy farms.

\section{CONCLUSIONS}

The present study described the adoption of biosecurity practices on Canadian dairy farms. We concluded that most biosecurity practices have not been widely adopted, which is similar to previous studies conducted in other countries. Multiple correspondence analysis allowed us to visualize that adoption of biosecurity practices was associated with demographic variables such as geographical region, type of housing, herd milk production, and organic status. The present study showed that implementation of biosecurity practices on Canadian dairy farms still needs to be promoted. Moreover, the results can be used as a benchmark to support the recommendations for biosecurity plans by the national standard. Finally, the variability of the adoption of biosecurity practices by geographical region, herd milk production, and type of housing highlights that different types of farms in different regions will have different priorities for implementing these plans.

\section{ACKNOWLEDGMENTS}

The study was funded by the Dairy Cluster 2 Research program through the Canadian Agri-Science Clusters Initiative (Dairy Farmers of Canada, Agriculture and Agri-Food Canada, Canadian Dairy Commission, and Natural Sciences and Engineering Research Council; Ottawa, ON, Canada). The authors acknowledge Ashique Rahman (Saint-Hyacinthe, QC, Canada) and the technical staff for their contribution to questionnaire building and data collection. Greetings are extended to the participating Canadian dairy farmers and the provincial milk boards for their willingness to contribute to the study.

\section{REFERENCES}

Barkema, H. W., M. A. G. von Keyserlingk, J. P. Kastelic, T. J. G. M. Lam, C. Luby, J.-P. Roy, S. J. LeBlanc, G. P. Keefe, and D F. Kelton. 2015. Invited review: Changes in the dairy industry affecting dairy cattle health and welfare. J. Dairy Sci. 98:7426-7445. https://doi.org/10.3168/jds.2015-9377.

Bates, T. W., M. C. Thurmond, and T. E. Carpenter. 2001. Direct and indirect contact rates among beef, dairy, goat, sheep, and swine herds in three California counties, with reference to control of potential foot-and-mouth disease transmission. Am. J. Vet. Res. 62:1121-1129. https://doi.org/10.2460/ajvr.2001.62.1121.

Bauman, C. A., H. W. Barkema, J. Dubuc, G. P. Keefe, and D. F. Kelton. 2018. Canadian National Dairy Study: Herd-level milk quality. J. Dairy Sci. 101:2679-2691. https://doi.org/10.3168/jds .2017-13336.

Brennan, M. L., and R. M. Christley. 2012. Biosecurity on cattle farms: A study in north-west England. PLoS One 7:e28139. https: //doi.org/10.1371/journal.pone.0028139.

CDIC (Canadian Dairy Information Center). 2015. Overview of the Canadian dairy industry at the farm. Accessed Oct. 5, 2017. http: //www.dairyinfo.gc.ca/ index_e.php.

CFIA (Canadian Food Inspection Agency). 2013a. Biosecurity for Canadian dairy farms: National standard. CFIA P0836-13. Canadian Food Inspection Agency, Ottawa, ON, Canada.

CFIA (Canadian Food Inspection Agency). 2013b. Biosecurity for Canadian dairy farms: Producer planning guide. CFIA P0862E-13. Canadian Food Inspection Agency, Ottawa, ON, Canada.

Croyle, S. L., C. G. R. Nash, C. Bauman, S. J. LeBlanc, D. B. Haley, D. K. Khosa, and D. F. Kelton. 2018. Training method for animalbased measures in dairy cattle welfare assessments. J. Dairy Sci. 101:9463-9471. https://doi.org/10.3168/jds.2018-14469.

Dargatz, D. A., F. B. Garry, and J. L. Traub-Dargatz. 2002. An introduction to biosecurity of cattle operations. Vet. Clin. North Am. Food Anim. Pract. 18:1-5. https://doi.org/10.1016/S0749 -0720(02)00002-6.

DEFRA (Department for Environment, Food and Rural Affairs). 2003. Biosecurity guidance to prevent the spread of animal diseases. Accessed Jan. 28, 2019. www.nonnativespecies.org/ downloadDocument.cfm?id $=615$.

Denis-Robichaud, J., R. L. A. Cerri, A. Jones-Bitton, and S. J. LeBlanc. 2016. Survey of reproduction management on Canadian dairy farms. J. Dairy Sci. 99:9339-9351. https://doi.org/10.3168/jds .2016-11445.

Dillman, D. A., J. D. Smyth, and L. M. Christian. 2008. Internet, Mail, and Mixed-Mode Surveys: The Tailored Design Method. 3rd ed. Wiley, Hoboken, NJ.

Dohoo, I. R., S. W. Martin, and H. Stryhn. 2009. Veterinary Epidemiologic Research. 2nd ed. VER Inc., Charlottetown, PE, Canada.

Emanuelson, U., K. Sjöström, and N. Fall. 2018. Biosecurity and animal disease management in organic and conventional Swedish dairy herds: A questionnaire study. Acta Vet. Scand. 60:23. https: //doi.org/10.1186/s13028-018-0376-6.

Erskine, R. J., P. C. Bartlett, T. M. Byrem, C. L. Render, C. Febvay, and J. T. Houseman. 2012. Association between bovine leukemia virus, production, and population age in Michigan dairy herds. J. Dairy Sci. 95:727-734. https://doi.org/10.3168/jds.2011-4760.

Gilbert, M., A. Mitchell, D. Bourn, J. Mawdsley, R. Clifton-Hadley, and W. Wint. 2005. Cattle movements and bovine tuberculosis in Great Britain. Nature 435:491-496. https://doi.org/10.1038/ nature03548.

Husson, F., S. Lê, and J. Pagès. 2017. Exploratory Multivariate Analysis by Example Using R. 2nd ed. Taylor \& Francis, Boca Raton, FL.

Josse, J., M. Chavent, B. Liquet, and F. Husson. 2012. Handling missing values with regularized iterative multiple correspondence analysis. J. Classif. 29:91-116. https://doi.org/10.1007/s00357-012 -9097-0.

Kristensen, E., and E. B. Jakobsen. 2011. Danish dairy farmers' perception of biosecurity. Prev. Vet. Med. 99:122-129. https://doi .org/10.1016/j.prevetmed.2011.01.010 
Kuster, K., M. E. Cousin, T. Jemmi, G. Schüpbach-Regula, and I. Magouras. 2015. Expert opinion on the perceived effectiveness and importance of on-farm biosecurity measures for cattle and swine farms in Switzerland. PLoS One 10:e0144533. https://doi.org/10 .1371/journal.pone.0144533.

Laanen, M., D. Persoons, S. Ribbens, E. de Jong, B. Callens, M. Strubbe, D. Maes, and J. Dewulf. 2013. Relationship between biosecurity and production/antimicrobial treatment characteristics in pig herds. Vet. J. 198:508-512. https://doi.org/10.1016/j.tvjl 2013.08.029.

Lindberg, A., and H. Houe. 2005. Characteristics in the epidemiology of bovine viral diarrhea virus (BVDV) of relevance to control. Prev. Vet. Med. 72:55-73. https://doi.org/10.1016/j.prevetmed 2005.07.018

Meyling, A., H. Houe, and A. M. Jensen. 1990. Epidemiology of bovine virus diarrhoea virus. Rev. Sci. Tech. 9:75-93.

Moore, D. A., D. A. Leach, D. Bickett-Weddle, K. Andersen, A. R. Castillo, C. A. Collar, G. Higginbotham, N. Peterson, B. Reed, and M. L. Hartman. 2010. Evaluation of a biological risk management tool on large western United States dairies. J. Dairy Sci. 93:4096-4104. https://doi.org/10.3168/jds.2010-3272.

Negrón, M., E. A. Raizman, R. Pogranichniy, W. M. Hilton, and M. Lévy. 2011. Survey on management practices related to the prevention and control of bovine viral diarrhea virus on dairy farms in Indiana, United States. Prev. Vet. Med. 99:130-135. https://doi .org/10.1016/j.prevetmed.2010.12.008.

Neves, R. C., and S. J. LeBlanc. 2015. Reproductive management practices and performance of Canadian dairy herds using automated activity-monitoring systems. J. Dairy Sci. 98:2801-2811. https://doi.org/10.3168/jds.2014-8221.

Nöremark, M., J. Frössling, and S. S. Lewerin. 2010. Application of routines that contribute to on-farm biosecurity as reported by Swedish livestock farmers. Transbound. Emerg. Dis. 57:225-236. https://doi.org/10.1111/j.1865-1682.2010.01140.x.

Nöremark, M., J. Frössling, and S. S. Lewerin. 2013. A survey of visitors on Swedish livestock farms with reference to the spread of animal diseases. BMC Vet. Res. 9:184-194. https://doi.org/10.1186/ 1746-6148-9-184.

Olde Riekerink, R. G., H. W. Barkema, D. T. Scholl, D. E. Poole, and D. F. Kelton. 2010. Management practices associated with the bulk-milk prevalence of Staphylococcus aureus in Canadian dairy farms. Prev. Vet. Med. 97:20-28. https://doi.org/10.1016/ j.prevetmed.2010.07.002.

Oliveira, L., and P. L. Ruegg. 2014. Treatments of clinical mastitis occurring in cows on 51 large dairy herds in Wisconsin. J. Dairy Sci. 97:5426-5436. https://doi.org/10.3168/jds.2013-7756.

Oliveira, V. H. S., J. T. Sørensen, and P. T. Thomsen. 2017. Associations between biosecurity practices and bovine digital dermatitis in Danish dairy herds. J. Dairy Sci. 100:8398-8408. https://doi.org/ $10.3168 /$ jds.2017-12815.

Pieper, L., U. S. Sorge, T. DeVries, A. Godkin, K. Lissemore, and D. Kelton. 2015. Comparing ELISA test-positive prevalence, risk factors and management recommendations for Johne's disease prevention between organic and conventional dairy farms in Ontario,
Canada. Prev. Vet. Med. 122:83-91. https://doi.org/10.1016/j .prevetmed.2015.09.004.

R Core Team. 2015. A Language and Environment for Statistical Computing. R Foundation for Statistical Computing, Vienna, Austria.

Radke, B. R., M. McFall, and S. M. Radostits. 2002. Salmonella muenster infection in a dairy herd. Can. Vet. J. 43:443-453.

Raymond, M. J., R. D. Wohrle, and D. R. Call. 2006. Assessment and promotion of judicious antibiotic use on dairy farms in Washington State. J. Dairy Sci. 89:3228-3240. https://doi.org/10.3168/jds .S0022-0302(06)72598-X

Ridge, S. E., C. Heuer, N. Cogger, A. Heck, S. Moor, I. M. Baker, and S. Vaughan. 2010. Herd management practices and the transmission of Johne's disease within infected dairy herds in Victoria, Australia. Prev. Vet. Med. 95:186-197. https://doi.org/10.1016/j .prevetmed.2010.05.001.

Ritter, C., J. Jansen, K. Roth, J. P. Kastelic, C. L. Adams, and H. W. Barkema. 2016. Dairy farmers' perceptions toward the implementation of on-farm Johne's disease prevention and control strategies. J. Dairy Sci. 99:9114-9125. https://doi.org/10.3168/jds.2016 $-10896$.

Rossi, G., R. L. Smith, S. Pongolini, and L. Bolzoni. 2017. Modelling farm-to-farm disease transmission through personnel movements: From visits to contacts, and back. Sci. Rep. 7:2375. https://doi .org/10.1038/s41598-017-02567-6.

Sanson, R. L., G. Struthers, P. King, J. F. Weston, and R. S. Morris. 1993. The potential extent of transmission of foot-and-mouth disease: A study of the movement of animals and materials in Southland, New Zealand. N. Z. Vet. J. 41:21-28. https://doi.org/ 10.1080/00480169.1993.35730.

Sarrazin, S., A. B. Cay, J. Laureyns, and J. Dewulf. 2014. A survey on biosecurity and management practices in selected Belgian cattle farms. Prev. Vet. Med. 117:129-139. https://doi.org/10.1016/j .prevetmed.2014.07.014.

Sayers, R. G., M. Good, and G. P. Sayers. 2014. A survey of biosecurity-related practices, opinions and communications across dairy farm veterinarians and advisors. Vet. J. 200:261-269. https://doi .org/10.1016/j.tvjl.2014.02.010.

Sayers, R. G., G. P. Sayers, J. F. Mee, M. Good, M. L. Bermingham, J. Grant, and P. G. Dillon. 2013. Implementing biosecurity measures on dairy farms in Ireland. Vet. J. 197:259-267. https://doi.org/10 $.1016 / j . t v j l .2012 .11 .017$.

Shortall, O., M. Green, M. Brennan, W. Wapenaar, and J. Kaler. 2017. Exploring expert opinion on the practicality and effectiveness of biosecurity measures on dairy farms in the United Kingdom using choice modeling. J. Dairy Sci. 100:2225-2239. https:// doi.org/10.3168/jds.2016-11435.

Thurmond, M. C., and J. P. Picanso. 1990. A surveillance system for bovine abortion. Prev. Vet. Med. 8:41-53. https://doi.org/10 .1016/0167-5877(90)90021-9.

Villarroel, A., D. A. Dargatz, V. M. Lane, B. J. McCluskey, and M. D. Salman. 2007. Suggested outline of potential critical control points for biosecurity and biocontainment on large dairy farms. J. Am. Vet. Med. Assoc. 230:808-819. https://doi.org/10.2460/ javma.230.6.808. 